\title{
PENGETAHUAN TENTANG KESEHATAN REPRODUKSI DENGAN KEJADIAN PERNIKAHAN DINI PADA PUS
}

\author{
Fera Riswidautami Herwandar ${ }^{1}$, Yuni Gustiar ${ }^{2}$, \\ STIKes Kuningan STIKes Kuningan ${ }^{12}$ \\ februari rabu.fera88@yahoo.co.id
}

\begin{abstract}
The problems of reproductive health knowledge with the incidence of early marriage in Indonesia is still found in rural areas, among others influenced by the knowledge, the characteristics of the physical environment, economic and social culture. Based on the results of a preliminary study in the Village Purwawinangun, interviews were conducted to 10 PUS known to most of them do not know the impact of early marriages on reproductive health. The purpose of this study to identify there a relationship between knowledge about reproductive health with pernikhan incident early on EFA in Sub Purwawinangun. Research type used is analytic with cross sectional design. The respondents totaled 135 respondents were taken by total population sampling. Data were collected using secondary data is data that is seen from the number of marriages in the can from the village and primary data using a questionnaire with interview research shows that the level of knowledge about reproductive health that respondents with good knowledge level of $14.8 \%$ (20 respondents), just as much as $71.2 \%$ (96 respondents) and less than 14\% (19 respondents). Conclusion The level of knowledge about reproductive health that respondents with good knowledge level of 14.8\%), just as much as $71.2 \%$ and less than 14\%). The results of this study are expected to be material information or input for EFA in the village Puerwawinangun, so they are better prepared to plan a wedding.
\end{abstract}

Keywords: reproductive health; the incidence of early marriage

\begin{abstract}
Permasalahan pernikahan dini di Indonesia masih dijumpai pada daerah pedesaan, diantaranya dipengaruhi oleh pengetahuan, karakteristik lingkungan fisik, ekonomi dan sosial budaya masyarakat. tahun 2014 dari 288.318 PUS sebanyak 281.243 (24,3\%) PUS yang melakukan pernikahan dini. Berdasarkan hasil study pendahuluan di Kelurahan Purwawinangun, hasil wawancara yang dilakukan kepada 10 PUS diketahui sebagian besar mereka tidak mengetahui dampak dari pernikahan dini terhadap kesehatan reproduksi. Tujuan penelitian ini untuk mengidentifikasi adakah hubungan antara pengetahuan tentang kesehatan reproduksi dengan kejadian pernikhan dini pada PUS di Kelurahan Purwawinangun.Jenis Penelitian yang digunakan adalah analitik dengan rancangan penelitian cross sectional. Responden penelitian berjumlah 135 responden yang diambil secara total population sampling. Pengambilan data dilakukan dengan menggunakan data sekunder yaitu data yang dilihat dari jumlah perkawinan yang di dapat dari kelurahan dan data primer dengan menggunakan kuesioner dengan cara wawancara. Data tersebut kemudian dilakukan uji statistik dengan menggunakan SPSS versi 16 for windows, diperoleh nilai $\mathrm{P}$ value $=0,002$, sedangkan $\alpha=0,05$ karena nilai $\mathrm{P}=0,05(0,002<0,05)$. Kesimpulan tingkat pengetahuan responden tentang kesehatan reproduksi yaitu sebagian besar responden dengan tingkat pengetahuan cukup sebanyak $71,2 \% \%$ ). Hasil penelitian ini diharapkan agar menjadi bahan informasi atau masukan bagi PUS di kelurahan Puerwawinangun, sehingga mereka lebih siap dalam merencanakan pernikahan.
\end{abstract}

Kata kunci: Kesehatan reproduksi; kejadian pernikahan dini 


\section{PENDAHULUAN}

\section{Latar Belakang}

Data terbaru dari Badan Pusat Statistik (BPS) bekerjasama dengan Badan Koordinasi Keluarga Brencana (BKKBN) provinsi Jawa Barat menunjukkan pada tahun 2014 dari 288.318 PUS sebanyak $281.243(24,3 \%)$ PUS yang melakukan pernikahan dini. Dan sebagian diantaranya kurang mengetahui tentang kesehatn reproduksi. Data dari Pusat Penelitian Kependudukan Universitas Padjajaran ( UNPAD) bekerja sama dengan BKKBN Jawa Barat melaporkan data tahun 2015 terdapat sebanyak 12.975.458 kartu keluarga (KK). Dan 2357 PUS yang melakukan pernikahan dini dengan alas an karena kehendak orang tua, karena repaksa dan ada juga karena hamil diluar nikah. Umur kawin muda di daerah pegunungan masih tinggi yaitu $36,7 \%$ kawin pertama antara umur 12-14 tahun, 56,7\% umur 15-19 tahun dan 6,6\% umur 20-24 tahun, dengan faktor yang melatarbelakangi adalah rendahnya tingkat pengetahuan dan budaya. Pernikahan dini banyak terjadi pada kelompok masyarakat miskin yang ditandai dengan pendapatan yang rendah, kurangnya pendidikan, kurangnya kesehatan, dan kurangnya aset (Oyortey \& Pobi, 2013). Menikah dini di negara berkembang termasuk Indonesia berkaitan dengan aspek ekonomi, pendidikan, kependudukan dan sosio kultural. Di Indonesia pernikahan usia dini masih ada terutama di daerah pedesaan (Nurwati, 2014).

Permasalahan kesehatan reproduksi remaja termasuk pernikahan dini di Indonesia masih dijumpai pada daerah pedesaan. Perkawinan dini di pedesaan diantaranya dipengaruhi oleh pengetahuan, karakteristik lingkungan fisik, ekonomi dan sosial budaya masyarakat (Hanum, 2013). Median usia kawin pertama Indonesia berada pada usia 19,8 tahun, sedangkan median usia kawin pertama di pedesaan adalah 17,9 tahun (BPS \& ORC Marco, 2014). Angka ini mengindikasikan bahwa separuh dari pasangan usia subur di Indonesia menikah di bawah usia 20 tahun. Begitu juga di kabupaten kuningan didapatkan data bahwa sekitar 9.542.526 Pasangan Usia Subur (PUS) dan 100 pasangan usia subur yang melakukan pernikahan dini. Berdasarkan data di kelurahan purwawinangun pada tahun 2015 terdapat 135 pasangan usia subur (PUS) dan banyak ditemukan usia dibwah 20 tahun yang sudah melakukan pernikahan dini pada tahun 2015. Hasil wawancara yang dilakukan kepada 10 PUS diketahui sebagian besar mereka tidak mengetahui dampak dari pernikahan dini terhadap kesehatan reproduksi. Berdasarkan latar belakang diatas maka peneliti merasa tertarik untuk melakukan penelitian tentang "hubungan antara pengetahuan tentang kesehatan reproduksi dengan kejadian pernikahan dini pada PUS di kelurahan Purwawinangun kabupaten Kuningan tahun 2015".

Tujuan Penelitian

Tujuan Umum

Mengetahui hubungan antara pengetahuan tentang kesehatan reproduksi dengan kejadian pernikahan dini pada PUS di Kelurahan Purwawinangun Kabupaten Kuningan.

Tujuan Khusus

1. Mengidentifaksi terjadinya pernikahan dini di kelurahan Purwawinangun kabupaten Kuningan.

2. Mengidintifikasi gambaran pengetahuan tentang kesehatan reproduksi pada PUS di kelurahan Purwawinangun Kabupaten Kuningan.

3. Menganalisis hubungan antara pengetahuan tentang kesehatan reproduksi dengan kejadian pernikahan dini pada PUS di kelurahan Purwawinangun Kabupaten Kuningan

\section{Hipotesis}

Hipotesis adalah jawaban sementara dari suatu penelitian. Hipotesis Alternatif adalah yang menyatakan ada hubungan suatu kejadian antara dua kelompok (Notoatmodjo, 2010 : 105). Hipotesis dalam penelitian ini yaitu: Terdapat hubungan antara tingkat pengetahuan tentang kesehatan reproduksi dengan kejadian pernikahan dini.

\section{METODE}


Penelitian ini penulis menggunakan jenis penelitian Analitik. Menurut Badriah (2009:16), analitik yaitu suatu metode penelitian yang menganalisis dan menyajikan data secara sistematik sehingga dapat lebih mudah untuk dipahami. Rencana desain dalam penelitian ini penulis menggunakan cross sectional. Menurut Badriah (2012:27), Penelitian cross sectional atau lintas-bagian adalah penelitian yang mengukur prevalensi penyakit. Oleh karena itu seringkali disebut sebagai peneltian prevalensi. Penelitian ini bertujuan untuk mempelajari hubungan paparan dengan cara cara mengamati suatu paparan dean penyakit secara serentak, pada individu dari populasi tunggal pada satu saat atau periode tertentu.

Populasi dari penelitian ini adalah seluruh pasangan usia subur (PUS) di Kelurahan Purwawinangun pada pernikahan tahun 2015 sebanyak 135 Pasangan Usia Subur. Teknik sampling yang digunakan dalam penelitian ini adalah teknik total sampling yaitu pengambilan sampel dengan populasi total yang digunakan sebagai responden. Adapun variabel bebas dalam penelitian ini adalah pengetahuan PUS tentang kesehatan reproduksi. Adapun variabel terikat dalam penelitian ini adalah kejadian pernikahan dini Dalam penelitian ini menggunakan istrumen kuesoner dengan wawancara terbuka.

Adapun dalam penelitian ini menggunakan data primer yaitu data yang di dapatkan langsung dari responden. Data sekunder dalam penelitian ini adalah data pernikahan yang di dapat dari Kantor Kelurahan Purwawinangun.

Analisis univariat dilakukan melihat gambaran tiap variabel dari hasil penelitian, dalam analisis ini hanya menggunakan distribusi dan persentase dari tiap variabel. Analisis univariat menggunakan distribusi frekuensi relatif dimana frekuensi tiap kelas diubah dalam bentuk persen (\%). Perubahan menjadi persen dilakukan dengan membagi frekuensi (f) dengan jumlah hasil observasi (N) dan dikalikan 100\% (Notoatmodjo, 2002) dengan rumus:

Keterangan :

$\mathrm{P}=$ Persentase

$f=$ Frekuensi

$\mathrm{N}=$ Jumlah Responden

Analisis Bivariat

Uji statistik yang dilakukan adalah $C h i$ Square untuk melihat hubungan dua variabel yaitu variabel independen dengan variabel dependen yang keduanya berbentuk kategori.

\section{Hasil Penelitian}

Berdasarkan penelitian yang dilaksanakan pada tanggal 20-24 Juni 2016, dengan sampel seluruh PUS di SMP di kelurahan Purwawinangun kabupaten Kuningan tahun 2015 yaitu sebanyak 135 responden dengan judul hubungan antara pengetahuan tentang kesehatan reproduksi dengan kejadian pernikahan dini pada PUS di kelurahan Purwawinangun kabupaten Kuningan tahun 2015. Penyajian hasil penelitian masing-masing variabel dapat terlihat pada tabeltabel berikut ini :

Analisis Univariat

Tabel 1. Distribusi Frekuensi tingkat pengetahuan PUS tentang kesehatan Reproduksi

$$
P=\underset{N}{f} \mathrm{x} 100 \%
$$


Berdasarkan tabel 5.1.1 Dari jumlah responden sebanyak 135 orang ternyata tingkat pengetahuan tentang kesehatan reproduksi sebagian besar adalah kategori cukup sebanyak 71,2\% (96 responden).

\begin{tabular}{|c|c|c|c|}
\hline No & $\begin{array}{c}\text { Tingkat } \\
\text { Pengetahu } \\
\text { an }\end{array}$ & $\mathrm{n}$ & Persentase (\%) \\
\hline 1. & Baik & 20 & 14,8 \\
\hline 2. & Cukup & 96 & 71,2 \\
\hline 3. & Kurang & 19 & 14 \\
\hline \multicolumn{2}{|c|}{ Total } & 135 & $100 \%$ \\
\hline
\end{tabular}

Tabel 2. Distribusi Frekuensi Kejadian Pernikahan Dini

\begin{tabular}{|c|c|c|c|}
\hline $\begin{array}{c}\mathrm{N} \\
\mathrm{o}\end{array}$ & $\begin{array}{c}\text { Kejadian } \\
\text { pernikahan } \\
\text { dini }\end{array}$ & $\mathrm{n}$ & Persentase (\%) \\
\hline 1. & $\begin{array}{c}\text { Pernikahan } \\
\text { terpaksa }\end{array}$ & 39 & 28,8 \\
\hline 2. & $\begin{array}{c}\text { Pernikahanke } \\
\text { hendak orang } \\
\text { tua }\end{array}$ & 84 & 62,2 \\
\hline 3. & $\begin{array}{c}\text { Hamil } \\
\text { diluar } \\
\text { nikah }\end{array}$ & 12 & 9 \\
\hline \multicolumn{2}{|l|}{ Total } & 135 & $100 \%$ \\
\hline
\end{tabular}

Berdasarkan tabel 5.1.2 Dari jumlah responden sebanyak 135 orang diketahui bahwa kejadian pernikahan dini sebagian besar menkah karena kehendak orang tua sebanyak 84 responden $(62,2 \%)$.

\section{Kelurahan Purwawinangun Kabupaten Kuningan}

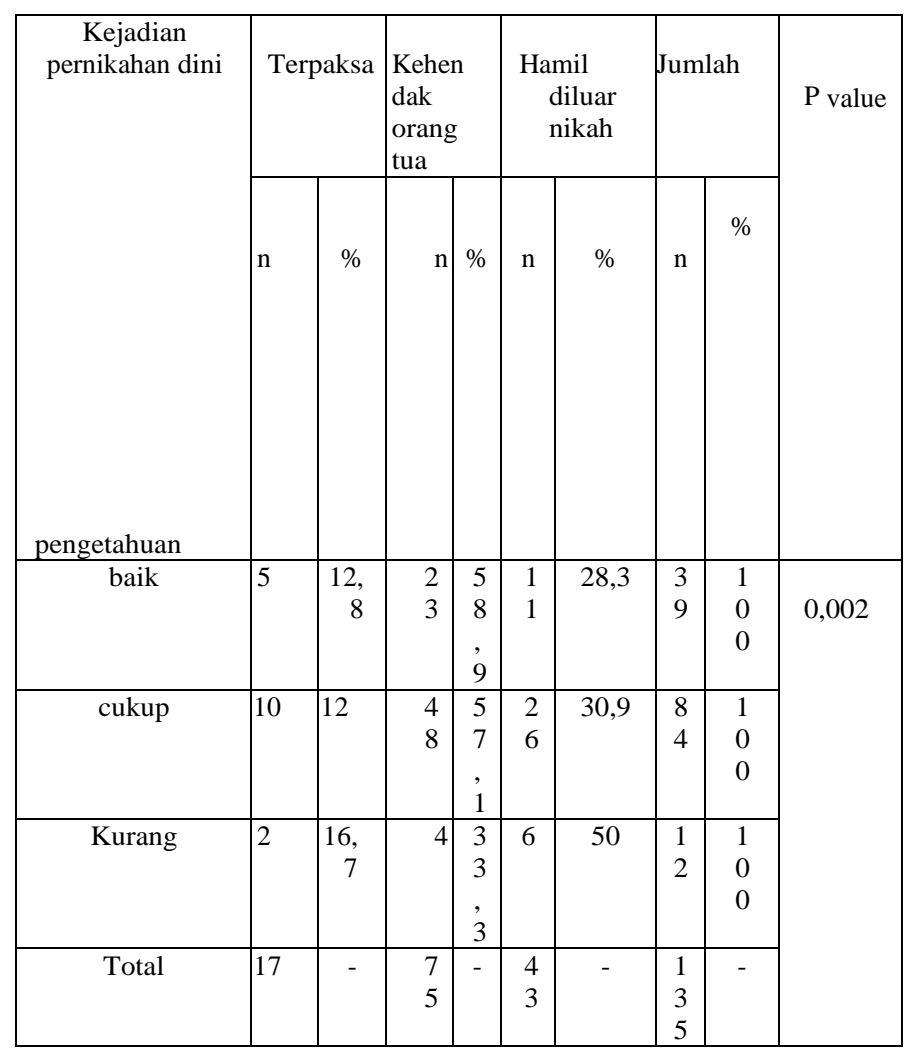

Berdasarkan tabel 5.1.3 dari jumlah 39 responden sebagian besar yang berpengetahuan baik sebanyak $(58,9 \%)$, karena kehendak orangtua, dari jumlah 84 responden sebagian besar yang berpengetahuan cukup sebanyak $(57,1 \%)$, karena kehendak orangtua, dari jumlah 12 responden yang berpengetahuan kurang sebanyak (50\%), karena hamil diluar nikah. Data tersebut kemudian dilakukan uji statistik dengan menggunakan SPSS versi 16 for windows, diperoleh nilai $\mathrm{P}$ value $=0,002$, sedangkan $\alpha=$ 0,05 karena nilai $\mathrm{P}=0,05(0,002<0,05)$.

\section{PEMBAHASAN}

1. Tingkat pengetahuan PUS tentang kesehatan reproduksi di kelurahan purwawinangun tahun 2015

Hasil penelitian tersebut sesuai dengan teori yang menyatakan bahwa 
pengetahuan tentang kesehatan reproduksi sangat penting bagi PUS. Peneliti berpendapat bahwa tingkat pengetahuan di kelurahan purwawinangun mayoritas cukup karena di kelurahan purwawinangun mayoritas berpendidikan Sekolah Menengah Atas (SMA) dan lingkungan yang sehat sehingga mayoritas sudah mengerti tentang kesehatan reproduksi. Pengetahuan merupakan hasil tahu, ini terjadi setelah orang melakukan penginderaan suatu objek tertentu. Penginderaan terjadi melalui panca indera yaitu indera penglihatan, pendengaran, penciuman, dan rasa. Sebagian besar pengetahuan manusia diperoleh dari mata dan telinga (Notoatmodjo, 2010:01). Begitu juga dengan hasil penelitian Marlinda (2010) bahwa tingkat pengetahuan PUS mengenai kesehatan reproduksi diantaranya dipengaruhi oleh karena kurangnya sumber informasi, kondisi lingkungan social remaja, dan keluarga. Dengan nilai $\mathrm{P}=0,003<0,05$.

\section{Kejadian pernikahan dini di kelurahan purwawinangun Kabupaten Kuningan}

Peneliti berpendapat bahwa penyebab pernikahan dini yaitu mayoritas karena kehendak orang tua, ini dikarenakan di kelurahan purwawinangun orang tua menganggap bahwa menikah lebih baik dari pada terjadi hal-hal yang tidak diinginkan sehingga banyak anak mereka yang dinikahkan setelah sekolah SMA Menurut Notoatmodjo

(2012:56) Banyak yang dapat mempengaruhi terjadinya pernikahan usia dini diantaranya yaitu pengetahuan. Faktor yang mempengaruhi pengetahuan menurut Notoatmodjo (2010:10-12) diantaranya yaitu pengalaman termasuk pengalaman dari orang tua sehingga pantas saja apabila hasil penelitian ini dipengaruhi oleh kehendak orang tua. Seperti hal nya dengan hasil penelitian Rismalinda (2010) bahwa kejadian pernikahan dini sebagian besar beralasan karena terpaksa dan karena hamil diluar nikah dengan nilai $\mathrm{P}=0,002<0,05$.

3. Hubungan Antara Pengetahuan Tentang Kesehatan Reproduksi Dengan Kejadian Pernikahan Dini Pada PUS Di Kelurahan

\section{Purwawinangun Kabupaten Kuningan}

Peneliti berpendapat bahwa tingkat pengetahuan kesehatan reproduksi yang tinggi mempunyai sedikit pengaruh seseorang tidak melakukan pernikahan dini, seperti para PUS yang memiliki tingkat pengetahuan yang baik tentang kesehatan reproduksi mereka melakukan pernikahan dini karena kehendak orang tua dan terpaksa bukan karena kehendak dirinya sendiri Data tersebut kemudian dilakukan uji statistik dengan menggunakan SPSS versi 16 for windows, diperoleh nilai $\mathrm{P}$ value $=0,002$, sedangkan $\alpha=0,05$ karena nilai $\mathrm{P}$ value < $0,05(0,002<0,05)$ maka keputusannya $\mathrm{Ha}$ diterima, artinya terdapat hubungan antara pengetahuan tentang kesehatan reproduksi dengan kejadian pernikahan dini pada PUS di kelurahan Purwawinangun kabupaten Kuningan tahun 2015.

Menurut Hyde (2012) Penyebab pernikahan dini terjadi karena keadaan terpaksa keluarga yang masih hidup di garis kemiskinan, untuk meringankan beban orang tuanya, maka anak perempuannya dikawinkan dengan orang yang dianggap mampu. Hasil penelitian tersebut sependapat dengan Soetjiningsih (2007) dalam bukunya mengemukakan bahwa pernikahan dini tidak hanya di pengaruhi oleh pengetahuan kesehatan reproduksi melainkan masih banyak faktor-faktor yang sangat berpengaruh terhadap kejadian pernikahan dini yaitu karena pernikahan terpaksa, pernikahan karena kehendak orang tua dan pernikahan karena hamil diluar nikah. Ada juga karena Faktor internal yaitu pengaruh yang berasal dari dalam diri kita. Bagaimana kita mengekspresikan perasaan, keinginan, dan pendapat tentang berbagai macam masalah. Menentukan pilihan ataupun mengambil keputusan bukan hal yang gampang. Dalam memutuskan sesuatu, kita harus punya dasar pertimbangan, wawasan dan prinsip yang matang. Faktor internal tersebut bisa dikatakan juga yaitu dari faktor Intellegence Quotient (IQ), Emotional Quotient (EQ), dan Spiritual Quotient (SQ).

Hasil penelitian ini juga sepaham dengan Penelitian unul di jakarta (2013) dengan judul hubungan antara pengetahuan 
tentang kesehatan reproduksi dengan kejadian pernikahan dini pada remaja 2013 yang ditinjau dari segi demografis menunjukkan bahwa pernikahan sebelum usia 18 tahun pada umumnya terjadi pada perempuan di Indonesia terutama di pedesaan. Hal ini dikarenakan keterpaksaan, kehendak orang tua dank arena hamil diluar nikah. Dengan nilai $\mathrm{P}=0,001<0,05$. Begitu juga dengan Penelitian munaroh (2012) di cirebon tentang hubungan antara pengetahuan kesehatan reproduksi dengan kejadian pernikahan dini tahun 2012 menyatakan bahwa 27,2\% remaja yang menikah sebelum berusia 16 tahun dengan pengetahuan kesehatan reproduksi cukup $(57,1 \%)$, Dengan nilai $\mathrm{P}=0,001<$ 0,05 .

\section{KESIMPULAN}

Berdasarkan hasil penelitian yang telah dilakukan pada tanggal 20-24 Juni 2016, mengenai hubungan antara pengetahuan tentang kesehatan reproduksi dengan kejadian pernikahan dini pada PUS di kelurahan Purwawinangun kabupaten Kuningan. Maka dapat diambil kesimpulan bahwa. Mayoritas tingkat pengetahuan PUS tentang kesehatan reproduksi berpengetahuan cukup. Mayoritas terjadinya pernikahan dini karena kehendak orang tua di Kelurahan Purwawinangun Kabupaten Kuningan. Terdapat hubungan antara pengetahuan tentang kesehatan reproduksi dengan kejadian pernikahan dini pada PUS di kelurahan Purwawinangun Kabupaten Kuningan.

\section{DAFTAR PUSTAKA}

1. Arikunto, S. (2010). Prosedur Suatu Penelitian Pendekatan Praktek. Jakarta: Rineka Cipta.

2. . (2010). Prosedur Suatu Penelitian Pendekatan Praktek. Jakarta: Rineka Cipta.

3. BKKBN, (2012). Diambil 6 Januari 2016. Tumbuh Kembang Remaja dalam $B K K B N$.go.id.

4. Badriah, D.L. 2012. Metodologi Penelitian Ilmu-Ilmu Kesehatan. Bandung: Multazam

5. Departemen Pendidikan Nasional. (2008). Kamus Besar Bahasa Indonesia Pusat
Bahasa. Jakarta : Gramedia Pustaka Utama.

6. Depkes RI. (2008). Kesehatan Reproduksi Remaja. Jakarta: Depkes RI.

7. Manuaba, IBG. (2009). Memahami Kesehatan Reproduksi pada Wanita. Jakarta:

8. Notoatmodjo, S. (2012). Metodologi Penelitian Kesehatan. Ed. Rev. Jakarta: Rineka Cipta.

9. Rahmawati, A. (2009). Kesehatan Reproduksi. Yogyakarta: Fitramaya.

10. Romauli, S. (2012). Kesehatan Reproduksi Buat Mahasiswa Kebidanan. Yogyakarta: Nuha Medika.

11. Sarwono, SW. (2007). Psikologi Remaja. Jakarta: Raja Gravindo Persada. Soetjiningsih, (2007). Tumbuh Kembang Remaja dan Permasalahannya. Jakarta: ICCLC.

12. Widyastuti, Yani dkk. (2009). Kesehatan Reproduksi. Yogyakarta: Fitramaya.

13. Dinas Kesehatan Kuningan (DINKES), (2015). Diambil 16 Januari 2016 dari http://www.dinkeskuningan.com

14. Munir, (2010) (t.t). Diambil Januari 2016 dari http://news.okezone.com/2010 tiap tahun remaja seks pra nikah meningkat.

15. Mukaromah, (2009) (t.t). Diambil 7 Januari 2016 dari http://eprints.undip.ac.id/

16. Nancy, P. (t.t). (2014) Kesehatan reproduksi Diambil 6 Januari 2016

17. Raden, (2007) (t.t). Diambil 7 Januari 2016 dari http: //www.kesrepro.info/?q= node 